\title{
NOÇÕES DE REPRESENTAÇÃO E A VERDADE NA SÉRIE CARRETÉIS DE IBERÊ CAMARGO
}

\section{NOTIONS OF REPRESENTATION AND THE TRUTH IN THE IBERE CAMARGO "CARRETÉIS" SERIES}

Mirian Martins Finger ${ }^{1}$

Jorge Luiz da Cunha

RESUMO: Este artigo aborda noçôes de representação balizadas em fragmentos pertencentes aos domínios da filosofia, da história e da arte. A intenção é analisar um recorte da série do artista Iberê Camargo, intitulada "Carretéis". Para fundamentar o estudo, que aborda a categoria representação, foram abordados autores como Cassirer (2001), Chartier (2012), Gombrich (2007), Goodman, (1976, 1995), Hayden White (1994, 2006, 2010), entre outros. Na primeira parte do texto expomos algumas noções de representação vinculadas à noção de verdade, tanto no que tange as narrativas dos eventos históricos, quanto às produçóes artísticas. Na segunda, analisamos duas obras da Série e verificar como Iberê representou plasticamente seu objeto de memória, o carretel. Assim, elucidamos que a transmissão da memória de infância do objeto carretel apresenta na série "Carretéis", distintas maneiras de representação e de verdade, tanto ao que concerne sua forma quanto sua simbologia.

Palavras-Chave: Representação; Carretéis; Iberê Camargo.

ABSTRACT: This article deals with notions of representation is based fragments belonging to the fields of philosophy, history and art. The intention is to analyze a cut of the series of the artist Iberê Camargo, titled "Carretéis". To base the study, which addresses the category of representation, authors such as Cassirer (2001), Chartier (2012), Gombrich (2007), Goodman, (1976, 1995), Hayden White $(1994,2006,2010)$. In the first part of the text we present some notions of representation linked to the notion of truth, both in terms of narratives of historical events and artistic productions. In the second one, we analyze two works of the Series and verify how Iberê plastically represented its object of memory, the reel. Thus, we elucidate that the transmission of the childhood memory of the spool object presents in the series "Carretéis", different ways of representation and truth, both regarding its form and its symbology.

Keywords: Rpresentation; Carretéis; Iberê Camargo.

Professora adjunta do Departamento de Artes Visuais da Universidade Federal de Santa Maria (UFSM), doutora em Epistemologia e História da Ciência pela Universidad Nacional de Tres de Febrero (UNTREF-AR) e doutora em História pelo Programa de Pós-graduação em História da Universidade Federal de Santa Maria (UFSM). mirianmfinger@gmail.com

2 Professor titular da Universidade Federal de Santa Maria (UFSM). Doutor em História Medieval e Moderna Contemporânea - University Hamburg, integra o quadro docente permanente do Programa de Pós-Graduaçáo em História e também do PPG em Educação da UFSM. jlcunha11@yahoo.com.br 


\section{INTRODUÇÃO}

Com A reverência da filosofia ao problema da representação alça debates relevantes ao estudo do conhecimento. Platão no livro X de A República (passagem 595 a - c, 2009), ao analisar a noçáo de mimese, diz que a imagem refletida no espelho é aparente tanto quanto a representação do real. Nesse sentido, Cassirer (2001, p. 13) afirma que Platão identificou o ser como um problema. Por isso, superou a explicaçáo mítica e cosmológica e tornou a organizaçáo sistêmica e teleológica da existência do ser. Todas as concepçóes científicas não são mais entendidas como reproduçóes de um determinado ser, mas sim como símbolos intelectuais concebidos por ele mesmo. O conceito de imagem transforma-se internamente. Consequentemente, a ingênua teoria da reprodução perde força e a exigência de semelhanças entre imagem e objeto é suplantada. Surge a expressão complexa por meio de uma "relação lógica, uma condição intelectual geral que deverá ser satisfeita pelos conceitos básicos do conhecimento físico" (CASSIRER, 2001, p. 15). Iberê Camargo, ao expor textualmente sobre arte, afirma que ela, a arte, se confunde com a vida. Para o artista a representaçáo artística não deve cobrir a "miséria do dia a dia como o colorido das orgias e da alienação do povo. Não faço mortalha colorida" (CAMARGO, 2009, p. 135). Sobre este âmbito, ao representar o carretel da memória infantil, Iberê náo busca o engodo do retrato que pode estar contido na representaçáo objetiva do objeto; ele corta, recorta, mutila em formas e cores aquele motivo que conscientemente reflete a memória e que se reflete inconsciente no suporte da tela. E é essa ausência de consciência plástica presente no carretel representado que rompe com qualquer teoria lógica de semelhança.

\section{NOÇÕES DE REPRESENTAÇÃO}

Abordado por Wittgenstein (1984), o tema da representação é definido como aquilo que relaciona o figurado com o afigurado a partir daquilo que existe de comum entre ambos, porém a semelhança de imagens náo é "o que faz com que minha representação de alguém seja minha representação desse alguém”. (WITTGENSTEIN, 1984, p. 176). Do mesmo modo, Rorty (1994, p. 17) diz que "Wittgenstein, Heidegger e Dewey concordam em que a noção do conhecimento como representação exata, tornada possível por processos mentais especiais e tornada inteligível através de uma teoria geral da representaçáo, deve ser abandonada." No mesmo trabalho ao discutir os dois tipos de representaçóes (intuiçóes e conceitos), que segundo ele estáo em desuso no movimento analítico, defende a representação de um ponto de vista holístico como o resultado da conversação entre o dado, o contingente e o necessário (RORTY, 1994, p. 174). Isso significa que devemos fazer distinçôes entre o que temos diante de nós, o que nossa mente acrescenta e o controle do que temos na mente, para a "reconstrução do racional' de nosso conhecimento." (RORTY, 1994, p. 175).

Rorty (1997) ainda critica algumas noçóes tradicionais da verdade, especialmente aquelas compreendidas na conjuntura epistemológica, por meio dochamado paradigma da representação. Ele afirma que são dois os modos dos seres humanos darem sentido a suas vidas, discorre sobre o realista e o pragmático, onde o primeiro é objetivo e "constrói-se 
a partir da descrição de si mesmo como estando em relação imediata com a realidade não-humana.", enquanto o segundo é solidário e "estabelece-se através da narração da estória de sua contribuição para a comunidade.” (RORTY, 1997, p. 37). Desta maneira, aplicando estas noçóes ao campo da história e da arte pode-se alegar que tanto a representação histórica quanto a artística, ao buscarem a objetividade, abandonam a solidariedade, ou seja, buscam a verdade por meio do que William James diz, segundo Rorty, "o que é bom para nós acreditarmos." (RORTY, 1997, p. 39, grifo do autor).

Já para o artista Kandinsky (1996), com seu olhar sobre a criação estética, a noção de representação está alicerçada na forma. Para ele "Só a forma, enquanto representação do objeto (real ou não real), enquanto delimitação puramente abstrata de um espaço, de uma superfície, pode existir por si mesma." (KANDINSKY, 1996, p. 74). Além disso, Kandinsky aborda as questôes formais e cromáticas da obra de arte e defende que enquanto "a forma é a expressão exterior do conteúdo interior", a cor é a ação sobre a alma "é o meio de exercer sobre ela uma influência direta. A cor é a tecla. $\mathrm{O}$ olho o martelo. A alma é o piano de inúmeras cordas. Quanto ao artista, é a mão que, com a ajuda desta ou daquela tecla, obtém da alma a vibração certa” (KANDINSKY, 1996, pp. 68; 74-142). Mesmo que sua explicação não aborde especificamente a representação, aliamos seus entendimentos referentes ao que compóe matericamente uma obra de arte como aquilo que é essencial a constituição de seu conteúdo, já que para ele a noção de expressão está intimamente vinculada a forma e a cor, pois ambas derivam do interior do artista. Desse modo, adotamos como uma a espécie de conceito de representação quando Kandinsky afirma que

\footnotetext{
Para cada artista (artista produtivo, e não 'seguidor'), seu modo de expressão é o melhor, visto que materializa aquilo que ele deve comunicar. Mas daí se tira amiúde a conclusão errônea de que esse meio de expressão, é, ou deveria ser, igualmente o melhor para os demais artistas. Como a forma não passa de uma expressão do conteúdo e o conteúdo difere segundo os artistas, segue-se que podem existir, na mesma época muitas formas diferentes que são igualmente boas. A necessidade cria a forma. (KANDINSKY, 1996, p. 143)
}

Tomando a forma como conceito de representação em Kandinsky, podemos afirmar que a importância dada a esta questão náo carece de objetividade, pois para ele é a forma que irá refletir o espirito de cada artista, "não é a forma (matéria), que é elemento essencial, mas o conteúdo (espírito)." (KANDISNKY, 1996, p. 144). O que ele nos dá a entender que se a obra nasce de uma necessidade interior o artista liberta-se da obrigatoriedade de representação objetiva.

Para os pragmáticos, na visão Rorty, "o desejo por objetividade não é o desejo de escapar das limitaçóes de uma comunidade, mas simplesmente o desejo de alcançar a maior concordância intersubjetiva possível, o desejo de estender a referência do pronome 'nós' táo longe quanto possível” (RORTY, 1997, p. 39). Assim, a verdade na representação histórica ou artística não está contida em nenhum tipo de correspondência de crenças e objetos relacionados a qualquer tipo de objetivação, o que não só dilata o lastro da interpretação histórica e artística, mas também liberta a linguagem, e a expressão artística, ao que tange a representação e a verdade como correspondência. 
Sob outra vertente, a abordagem da representação tomada por Bergson (1999) é construída por meio de uma teoria da imagem. O autor evidencia o processo originado na ação do corpo, ou seja, nosso corpo influencia o que nos circunda. Desse modo, a representaçáo não passa de uma reflexão da ação que exercemos sobre nosso corpo. Sobre este prisma, a concepção de representaçáo como mímese do mundo cai por terra, pois o entendimento do mundo a partir da subjetividade, que confere ao conhecimento a correlação entre ideias e coisas, para Bergson é falaciosa. Para ele, a representação como unidade do pensamento congelado, adotada pela filosofia clássica deve ser superada. Advoga que esta unidade é derivada de um processo artificial de um movimento, em função da estabilidade que o mundo exerce sobre nossa ação. $\mathrm{O}$ que em sua visão classifica a representação como algo que conhecemos somente porque agimos, o que a torna condicionada a ação e que só se estabelece na medida em que nossa ação se processa. Nossa percepção, no esclarecimento bergsoniano, em condição pura e isolada de nossa memória, não circula de nosso corpo aos outros corpos, ela se encontra no todo dos corpos primeiramente, depois se restringe lentamente e toma meu corpo como o centro. Uma imagem náo necessita ser percebida e representada para existir. Há uma distância neste sentido, o que mede "o intervalo entre a própria matéria e a percepção consciente que temos dela.” (BERGSON, 1999, p. 32). A passagem da presença a representação de nada necessita, pois se algo fosse necessário o intervalo seria intransponível, "e a passagem da matéria à percepção permaneceria envolvida em um impenetrável mistério” (BERGSON, 1999, p 32). Por exemplo, se tiver um carretel e a representação dele, como explico que a representação não é o que parece ser para mim? Quem sabe seja esta a contribuiçáo mais ilustre de René Magritte para com a história da arte, o jogo de palavras e imagens, caracterizado por sua icônica percepçáo a traição das imagens. Magritte, no início do século XX, mesmo já tendo rompido com a ideia de representação como imitação da natureza, ao representar "realisticamente" um cachimbo, vai além ao colocar a imagem como potência à traição. Atraído pela relação facultativa entre objetos do cotidiano e as abstraçóes da linguagem, Magritte explora a distância entre imagem e linguagem, o que proliferou em concepçóes de um sistema comum de comunicação que incitou a crítica à própria noção de representação. Na obra intitulada Ceci n'estpas une pipe (isto não é um cachimbo) (1928), o artista desconstrói o entendimento de que ali há um cachimbo, há sim, uma pintura de cachimbo. A conhecida frase "pintada" na tela sublinha o contrassenso central da representação e se reforça se considerarmos o texto contido na tela como pintura. Assim, a palavra utilizada para indicar um objeto não é o próprio objeto, o que se aplica também à sua imagem.

Na solução de Bergson a representação por ser "solidária à totalidade das outras imagens" (BERGSON, 1999, p. 33), alonga-se nas que a circundam, do mesmo modo que se dilata àquelas que a antecederam. "Para transformar sua existência pura e simples em representação, bastaria suprimir de uma só vez o que a segue, o que a precede, e também o que a preenche, não conservando mais do que sua crosta exterior, sua película superficial.” (BERGSON, 1999, p. 33).O que diferencia um carretel, um cachimbo, ou outro objeto presente, como objeto real, de sua representação é a ação em que se depara diante da situação de outras imagens, "de comunicar a totalidade daquilo que recebe, de opor a 
cada ação uma reação igual e contrária, de não ser, enfim, mais do que um caminho por onde passam em todos os sentidos as modificaçóes que se propagam na imensidão do universo.” (BERGSON, 1999, p. 33). A representaçáo, para Bergson, na ocasião em que passa ao ato, pelo comprometimento de prolongar-se e de se transformar em outra coisa, mesmo concretizada é sempre virtual e neutralizada. $\mathrm{O}$ carretel, como nosso exemplo, ao ser representado é convertido não por ser "iluminado", mas por apagar certas arestas que não interessam dele, de modo que seu resquício se destaca como um quadro em vez de conservar-se fixado no ambiente como uma coisa. (BERGSON, 1999, p. 34, grifo do autor). E sobre este aspecto, Bergson e Magritte são congruentes. Porém, cada qualidade que foi separada do carretel deverá juntar-se a ele, pois para cada propriedade do carretel que lhe é retirada aumenta o intervalo entre a sua representação. A representaçáo do carretel sem relaçáo com o próprio objeto apresenta dificuldades que aumentam quanto maior for a distância. $\mathrm{O}$ que significa então que para Bergson a representação deve preservar certas propriedades características do objeto? Não necessariamente, afinal o que interessa não é como nasce a percepçáo que temos do carretel, mas como ela se restringe, visto que seria por direito a imagem integral, mas ela se reduz em virtude de nossa vontade de recortar o que realmente interessa.

O recurso tomado por Goodman (1976) para a questão da compreensão de um quadro não é saber aplicar uma representação, mas sim classificá-lo. Não interessa o que ele denota e sim qual sua espécie. Assim como é possível classificar uma imagem de um carretel enquanto uma classe de objetos de costura, é possível classificar a imagem de um cavalo alado como qualquer coisa. Desse modo, a maioria das imagens pode ser classificada em imagem de carretel, imagem de dado, imagem de cadeira, etc. Mas, "o que costuma enganar-nos é que expressóes como 'imagem de’ e 'representação de' parecem predicados binários bem-educados, e podem por vezes ser interpretadas como tal." (GOODMAN, 1976, p. 21). Para Goodman, não há como adentrar cada um dos termos e quantificar suas partes, pois não são considerados dois termos, mas apenas um. Para isso, considera que são predicados unários indivisíveis, isto é, "formam uma proposição quando se aplicam a um único argumento” (D’OREY, 1999, Cap. VI, n. 83). Para evitar qualquer confusão Goodman sugere "imagem-de-cavalo-alado" ou "cavalo-alado" e explica que utiliza o dispositivo de hifenização

unicamente como uma ajuda no discurso técnico [...] Usarei "imagem-de-homem” sempre como abreviatura da maior e mais habitual expressão "imagem que representa um homem”, tomada como um predicado unário indivisível que não tem de se aplicar a todas ou apenas às imagens que representam um homem efetivamente existente. (GOODMAN, 1976, p. 22, n. 19)

Desse modo, Goodman náo usa "imagem-de-um-homem" como abreviatura de imagem pintada por um homem ou de imagem que pertença a um homem, pois uma imagem de um homem não é necessariamente uma imagem de um homem, mas antes uma imagem que representa um homem, assim como o cachimbo de Magritte. Portanto, quando dizemos que uma imagem simula um cavalo-alado, por exemplo, estamos dizendo que a imagem é uma imagem-de-cavalo-alado, mas não estamos dizendo que ela denota alguma coisa. 
Chartier em uma primeira noção de representação diz que representação é a

\begin{abstract}
imagem que remete a ideia e a memoria os objetos ausentes, e que nos apresenta tais como são". Nesse primeiro sentido, a representação nos permite ver o 'objeto ausente' (coisa, conceito ou pessoa), substituindo-o por uma 'imagem' capaz de representa-lo adequadamente. Representar, portanto, e fazer conhecer as coisas mediatamente pela 'pintura de um objeto', 'pelas palavras e gestos', 'por algumas figuras, por algumas marcas' - tais como os enigmas, os emblemas, as fabulas, as alegorias. (CHARTIER, 2011, p. 17).
\end{abstract}

Entretanto, Chartier vai mais longe e explora a noção de representação de maneira menos dicionarizada e mais epistemológica, pronunciando que

\begin{abstract}
Um dos dois modelos mais operacionais construídos para explorar o funcionamento da representação moderna - seja ela linguística ou visual - e o que propóe a tomada de consideração da dupla dimensão de seu dispositivo: na dimensão 'transitiva' ou transparente do enunciado, toda representação representa algo; na dimensão 'reflexiva, ou opacidade enunciativa, toda representação se apresenta representando algo. (CHARTIER, 2011, p. 18).
\end{abstract}

Na apresentação de "algo novo" dentro da História Cultural, Chartier toma os objetos por meio de suas formas e seus agentes, ou seja, suas representações do mundo social. Para orientar tais agentes devemos compreendê-los como símbolos. Assim, todas as categorias e todos os processos que constroem o mundo como representação são compreendidos como formas simbólicas. O que nos leva a entender que para Chartier o conceito de símbolo é a expansão culminante do conceito de representação. Mais uma vez, além de aderimos a noção de Chartier o aliamos a Goodman, pois uma imagem-de-carretel, por mais que se aproxime de uma letra $\mathrm{X}$, por exemplo, é um símbolo que representa um carretel.

No texto de Chartier, publicado na revista Annales (1989), intitulado O mundo como representação, o autor dispóe sobre a relação da representação tomada como "uma imagem presente e um objeto ausente, uma valendo pelo outro porque lhe é homólogo - traça toda teoria do signo do pensamento clássico, elaborada em sua maior complexidade pelos lógicos de Port Royal." (CHARTIER, 1989, p. 184). Sua complexidade permite discorrer diversas classes de signos e distinguir símbolos de outros signos. Nesta proposta de Port Royal, Chartier identifica que para que um signo seja inteligível é necessário identificar que há uma falta de compreensão da representaçáo, seja pela ausência de preparo daquele que o interpreta, que muitas vezes está vinculado às convençóes, seja pela '“extravagância' de uma relação arbitrária entre o signo e o significado” (CHARTIER, 1989, p. 185), o que leva à questáo das espécies de produção das semelhanças acolhidas e compartilhadas dos discursos. Para Chartier é o discurso que expressa as representaçóes e neste sentido, são as diferentes formas de apreensão do discurso que se percebe o real, e como são produzidos os sentidos, o que é deliberado por meio da relação entre o texto e o leitor. Uma das características dos discursos são seus modos diversos, assim como a pluralidade de sentidos que geram ao leitor. Sobre este olhar, o autor ainda afirma que são estas as categorizações e eliminações que compóem a estrutura social de certo tempo e espaço. Ao questionar a presença de estruturas sociais como algo que detém em si a realidade, as representações são apenas seu espelho. Enquanto as práticas que, múltiplas e contrariamente, conferem sentidos ao mundo rompem com a ideia de que os textos possuem um 
sentido em si mesmo. Desse modo, as representações se referem aos distintos modos de como os tempos e espaços de uma realidade social são constituídos através de categorizações, determinaçóes e fragmentações. Esta afirmação de Chartier nos permite agregar a ela as noçóes tanto de Goodman quanto de Gombrich quanto a representação, onde ambos adotam a convencionalidade, ou seja, o ambiente cultural, como determinantes aos sistemas de representação aderidos pelos indivíduos.

Outra explicação da noção de representação é a que a considera como causalidade. Nesse sentido, $x$ representa $y$, se $y$ interfere significativamente na cadeia causal que produziu $x$. Neste caso, $x$ pode ser tomado como um resquício de $y$ e a interpretação de $x$ é uma questão de dedução para um termo primeiro numa sequência causal (D'OREY 1999, p. 343). Consideramos o caso da pintura de um carretel que representa um carretel. A pintura de um carretel é tomada como um resquício do objeto carretel e sua interpretação é uma questão de dedução obtida, por meio de sua característica formal, por exemplo. Essa explicação, no entanto, não dá conta das representaçóes fictícias - como a representação de um cavalo-alado, por exemplo - nem daquelas representaçôes que representam um objeto como outro objeto - caso do carretel representado por Iberê como um brinquedo, por exemplo.

A representação como intencionalidade do autor da obra de arte é outra teoria que não se sustenta. Em primeiro lugar, porque podemos não ter acesso à intenção do artista. Em segundo lugar, porque o autor pode não ter a competência suficiente para convencer o espectador de sua intenção. Em último lugar, por causa do caráter convencional, pois o que pode ser um carretel para o artista pode ser uma ampulheta para o observador. Woolheim (2002) defende que aquilo que o artista representa não é qualquer coisa, mas algo específico ou meramente de um tipo específico, "pois toda pintura representacional representa alguma coisa de um tipo especial" (WOOLHEIM, 2002, p. 70). Desse modo, se a pintura estiver representando um objeto específico, estará representando tudo o que este objeto é. Ora, sabemos que náo é possível representarmos "tudo" o que um objeto é numa pintura. Se representarmos um carretel, podemos estar representando um brinquedo, mas não um conjunto de átomos, um pedaço de madeira ou de plástico. Se tudo pode ser um objeto, nada também pode, afinal nada pode ser copiado em plena posse de suas propriedades (GOODMAN, 1976, p. 6).

A noção de semelhança na representação abordada por Gombrich (2007), fundamentada na análise psicológica da representação pictórica, diz que a semelhança na representação tem a ver com "relaçóes". Tem a ver com o que ele chama de "acento pessoal", ou seja, o modo pessoal adotado pelo artista ou "estilo" e o olhar do observador. Para ele, a representação fiel de um objeto está muito mais vinculada às convençôes e a educação adquirida ao longo da vida, do que aos aspectos peculiares do objeto, pois "Toda a cultura e toda a comunicação dependem das interaçóes entre expectativa e observaçáo [...] a a relação entre o esperado e o experimentado." (GOMBRICH 2007, p. 53). O que significa que para Gombrich a semelhança é satisfeita à medida que obedece a relaçóes vinculadas ao que estamos habituados. Se tomarmos esta noção aos modos de representação adotados por Iberê ao longo da série Carretéis, é possível afirmar que, por mais que o artista não se aliasse 
a modismos estéticos contemporâneos nos diferentes períodos da série, encontramos alguns aspectos plásticos relacionados a alguns movimentos artísticos ou a artistas de sua época.

No âmbito da representaçáo convencional Gombrich e Goodman concordam. Porém, Goodman refere-se à representação como um sistema de símbolos, enquanto para Gombrich os símbolos são "ilusóes". Advoguemos então em defesa de Goodman e tomemos como exemplo o mesmo que Gombrich (2007, p. 4) utiliza em Arte e ilusão (2007); a saber, a figura do pato ou coelho - desenho tão explorado na filosofia e que saiu das páginas humoristas do semanário Die Fliegenden Blätter. (figura 1)

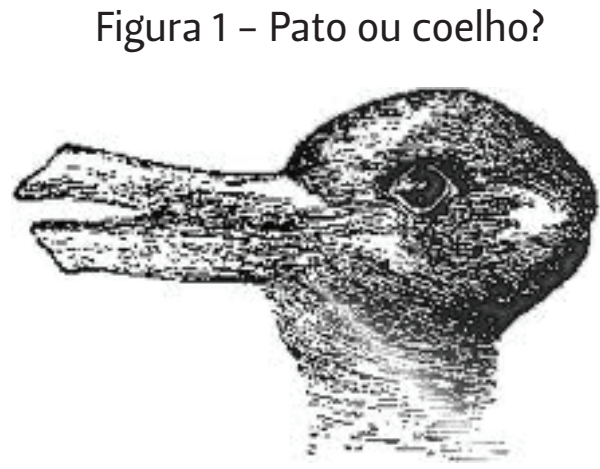

Fonte: Gombrich (2007, p. 4)

O pato aparece quando as orelhas do coelho se transformam em bico e vice-versa. Nosso olhar decifra-os porque nossas convençóes permitem conhecermos a forma de ambos. Mas, se mostrarmos o desenho a alguém que nunca tenha visto um pato ou um coelho, a ilusão desaparece, pois, o grau de semelhança exigido na teoria de Gombrich, não é suficiente para permitir a ilusão. Para ser um símbolo nenhum grau de imitação é suficiente ao constituir a relaçáo de referência demandada. O mesmo ocorre em um texto. Ainda que não saibamos interpretá-lo por não conhecermos o idioma, as palavras não deixam de fazer parte de um sistema de símbolos. Desse modo, Goodman defende que o objeto representado é referido por meio de um símbolo e a semelhança depende da interpretação de uma determinada situação e em que sentido a consideramos, já que ela é relativa e alterável culturalmente.

Dentro de uma crítica epistemológica à historiografia contemporânea, Hayden White se utiliza de categorias da literatura para análise historiográfica. Para Burke (2005), White é um dos colaboradores da nova visão de que o passado é como uma construção. Nesse âmbito, a questão da representação tomada por White (1995) refere-se à representação histórica. Neste modelo de representação White inverte a formulação debatida nas artes visuais - que busca verificar os elementos "históricos" de uma obra "realista", ao questionar quais são os componentes "artísticos" da historiografia "realista". Neste aspecto, o método empregado por White é por ele denominado "formalista" (WHITE, 1995, p. 19), onde procura identificar os elementos estruturais das descriçóes históricas de diversos historiadores do século XIX. Ao discorrer sobre “o fardo da história” White (1994)alerta sobre o equívoco das afirmações de que "a história é uma combinação de ciência e arte" 
e diz que o historiador deve operar considerando uma "perspectiva sobre o mundo que náo pretende exaurir a descrição ou a análise de todos os dados contidos na totalidade do campo dos fenômenos, mas oferece como um meio entre muitos de revelar certos aspectos desse campo" (WHITE, 1994, p.58-59, grifo do autor). White emite algumas comparaçóes entre a representação histórica e a artística. Para isso, aproveita a análise de Gombrich em Arte e ilusão (2007) e diz não ser relativista a afirmação deste, sobre as diferenças entre Constable e Cèzanne ao interpretar a mesma paisagem. Gombrich defende que é o estilo de cada artista - chamado por Gombrich, como dito acima, de "acento pessoal", que faz que cada artista represente a paisagem de forma distinta.

O estilo funciona como o que Gombrich denomina "sistema de notação", como "um protocolo provisório ou uma etiqueta" (WHITE, 1994, p. 59). White e Gombrich concordam que não há questionamentos referentes ao sistema adotado pelo artista que traduza de maneira objetiva o que foi representado. Do mesmo modo, para White

[...] o cosmopolitismo metodológico e estilístico promovido por este conceito de representação obrigaria os historiadores a abandonar a tentativa de retratar 'uma parcela particular da vida, do ângulo correto e na perspectiva verdadeira', expressou um famoso historiador anos atrás, e a reconhecer que não há essa coisa de visão única correta de algum objeto em exame, mas sim muitas visóes corretas, cada uma requerendo o seu próprio estilo de representação. (WHITE, 1994, p. 59, grifos do autor).

Neste sentido, pode-se dizer que há uma consonância entre White, Goodman e Cassirer justamente na compreensão de que não há apenas um mundo a ser interpretado, mas várias versóes de mundo. ${ }^{3}$ Notemos que para estes autores o mundo de uma versão verdadeira é uma construção, suas características não oferecem nada que seja independente de uma versão, mas se combinam com outras para fazer o mundo. Quando Goodman diz que fazemos mundos, isso significa que fazemos versóes e as versóes verdadeiras fazem mundos. No entanto, ele mantém uma questão em pauta: como fazer versóes verdadeiras quando a ação de fazer uma descrição verdadeira de um objeto é completamente incapaz de fazer o próprio objeto? Uma versão correta e seu mundo são diferentes. Uma versão que afirme que há um carretel sobre a mesa não é o mesmo carretel feito de letras. Mas, por outro lado, dizer que há um carretel sobre a mesa e dizer que o enunciado "há um carretel sobre a mesa" é verdadeiro, é a mesma coisa. O que importa para Goodmané que

[...] não podemos encontrar nenhum traço do mundo que seja independente de todas as versôes. Tudo o que se pode dizer como verdade de um mundo depende da ação de dizer - não do fato de que o que dizemos seja verdadeiro, senáo de que o que dizemos como verdade (ou como correto) participa e é relativo, a uma linguagem ou a outros sistemas de símbolos que utilizemos. (GOODMAN, 1995, p. 74)

Sobre o mesmo entendimento referente à multiplicidade de mundos, Jenkins abre seu texto Ordem(ns) do dia (2014) citando Ermarth com a seguinte afirmação: "A condição

3 A noção de "versão de mundo" abordada neste estudo refere-se à noção de Nelson Goodman. Para melhor compreensão, cf. GOODMAN, Nelson. Ways of worldmaking. Indianapolis: Hackett Publishing, 1978. 
discursiva [da pós-modernidade] não é apropriada á Hipótese do Mundo Único. Nem o valor pressuposto de neutralidade, nem ao projeto de objetivaçáo com sua ênfase no ponto de vista individual e na forme emergente." (EMEARTH, in JENSKINS, 2014, p. 51). Nesta obra, Jenkins (2014, p. 53) ainda argumenta que a história só pode ser ofertada por meio do presente, quando é "apresentada", o que entendemos como sua noção de "representação histórica". Para esclarecer melhor, Jenkins (2014, p. 62) busca apoio em Ankersmith para a ideia de história como "proposta". Esta ideia estaria centrada no entendimento de que ao invés de o fato histórico ser representado, é apresentado, pois quando representado está no lugar de uma realidade dada, e quando é apresentado, é criado a partir de uma realidade passada. Neste sentido, a realidade narrada náo estaria sendo apresentada novamente, mas apresentada de forma inédita com a liberdade de ser pensada, interpretada.

Do mesmo modo, a visão de que a arte e a ciência, e também a história, devam fazer uma cópia literal de uma realidade pressupostamente estática e "verdadeira", foi transcendida para White. E para o historiador é a oportunidade da se valer da dinamicidade de ambas para representar uma narrativa histórica também dinâmica. É possível perceber este dinamismo presente na história da arte; Gombrich (2007, p. 3) ao ponderar sobre a psicologia e o enigma do estilo artístico, diz que "Se a arte fosse apenas, ou principalmente, a expressão de uma visão pessoal, não poderia haver história da arte." Isso porque não seria possível adotar - como adotamos de costume - que é necessário uma "semelhança de 'família" entre uma obra que represente carretéis pintada com proximidade. Na mesma linha de juízo, mas sob o viés da leitura da história, Jenkins (2001, p. 52) reflete sobre a inevitável relatividade da história colocando esta afirmação em cheque. As respostas, tanto para Gombrich quanto para Jenkins, podem encontrar apoio onde o primeiro chama de "estilo" e o segundo de "emancipação". Ambos os modos são interpretativos. Para a arte é o que caracteriza plasticamente uma obra de arte e para a história é a liberdade de classificar esta obra de arte, seja no tempo, no espaço ou no estilo. Da mesma maneira, a interpretação dos eventos históricos trás para a representação esta "relatividade". Como diz Gombrich (2007, p. 5), "A representação não precisa ser arte, mas nem por isso é menos misteriosa." Entretanto, é imperativo tanto para o historiador quanto para o artista uma aproximação com o que está sendo representado, seja por métodos delineados, seja por esquemas de estilo, pensados a fim de ajustá-los as necessidades do tipo de representaçáo adotado, ou como diria Goodman, para uma versão de mundo. Os dispositivos adotados na narrativa histórica são semelhantes aos dispositivos pictóricos empregados por um pintor. A "verdade" de um fato, de um objeto, via interpretaçáo, passam a fazer parte de uma "realidade" integrante de outra versão de mundo, um mundo "verdadeiro em um sentido ficcional" (WHITE, 2010, p. 171).

Aos diversos tipos de interpretação da história White denomina "Meta-história", que como sinônimo de "Filosofia especulativa da história", afirma que não pode haver história restrita sem a hipótese de uma meta-história. Este pressuposto adota a oposição da vertente tradicional e rejeita o mito da objetividade. Ricouer (2007) também rejeita este o mito para a representação do discurso historiográfico. Sua posição é de aliar o fato de representar a 
história das práticas dos agentes sociais, aos historiadores que a narram de maneira erudita e criativa. "Existiria de fato uma relação mimética entre representação-operação, enquanto momento do fazer história e a representaçáo-objeto, enquanto momento de registrar a história” (RICOUER, 2007, p. 241). À maneira erudita e criativa descrita por Ricouer, podemos interpretar como a proposta de abertura à narrativa histórica de White. Este sustenta, que o historiador diante a uma sequência de eventos pode interpretá-los em formato de enredo, sejam de narrativas com formas de romance, de tragédia, de comédia. A "estória" que o historiador busca "encontrar" antecede ao enredo, mas é revelada representando uma estrutura reconhecível relacionada a um modelo essencialmente mítico. A história "revelada" de White compara-se ao que Goodman (1978, p. 131) chama de "revelação" àquilo que o artista faz ao dar um novo sentido ao que interpreta, e que dentro do "realismo" assumido pode-se dizer que a obra é "correta". É o realismo como "revelação", ou seja, o artista revela-nos aspectos invisíveis, outras possibilidades artísticas atingindo um novo grau de realismo. Este novo grau de realismo é aqui entendido segundo a concepção de Kandinsky (1996) que não se incomoda com as bifurcaçóes relacionadas ao real e ao abstrato. Para ele "não tem importância que o artista recorra a uma forma real ou abstrata, já que elas são interiormente equivalentes. A escolha há de ser deixada ao artista, que deve saber melhor que ninguém por qual meio ele é capaz de materializar mais claramente o conteúdo de sua arte.” (KANDINSKY 1996, p. 153). Isso significa que a relatividade do campo da representação pode abarcar interpretaçóes antitéticas, frequentando dicotomias inimagináveis. Porém, a aproximação com o fato ou objeto estudado deverá ser construída através de meticulosa apreciação da versão de mundo da qual está em jogo, ou seja, a verdade dependerá do sistema de classificação assumido pelo historiador ou pelo artista. Conforme Kandinsky (1996) não há mais uma dependência da representação ao realismo, a intenção é que haja uma independência entre o real o abstrato, sem que seja esquecido o agradável grau de complementaridade entre ambos.

\footnotetext{
Assim como o realismo reforça a ressonância interior pela eliminação do abstrato, a abstração reforça essa ressonância pela eliminação do real. No primeiro caso, era a beleza convencional, exterior e lisonjeira que impedia de ver; no segundo, o objeto exterior, ao qual os olhos estáo acostumados e que serve de suporte ao quadro, que desempenha esse papel. A 'compreensão' deste gênero de quadros exige a mesma libertação que a 'compreensáo' dos quadros realistas: também na presença deles devemos ser capazes de entender o mundo inteiro tal como ele é, sem acrescentar qualquer interpretação ligada a objetos. Essas formas abstratas (linhas, superfícies, manchas, etc.) não têm importância enquanto tais, mas unicamente por sua ressonância interior, por sua vida. Do mesmo modo, nas obras realistas não é o próprio objeto ou seu invólucro exterior que contam, mas sua ressonância interior, sua vida. (KANDINSKY, 1996, p. 150).
}

Seja qual for o método, realista ou abstrato, de escopo tropológico ou não, sempre será uma interpretaçáo do mundo. E aqui se encontram duas fundamentaçóes relevantes ao tema da representação. A primeira encontra-se em Gombrich $(2007,307)$ quando este afirma que "Não há realidade sem interpretação. [...] Uma interpretação alternativa pode expulsar a que é geralmente aceita e revelar um lampejo da realidade por trás dela." E a segunda em Jenkins (2014, p. 61), “[...], se aquilo que um dia foi realidade tem qualquer vida hoje, isso se deve inteiramente aos simulacros - à história - que os historiadores 
construíram dela [...]". Nesse sentido, se não existe nenhum mundo independente capaz de competir com uma versão, em que consiste a verdade e quais são os critérios para determiná-la? A resposta é que não devemos buscar a verdade na relação de uma versão com algo exterior a ela, mas sim em relação a suas próprias características. "Há não ser que uma estória histórica for apresentada como uma representação literal dos eventos reais, não podemos criticá-la como sendo verdadeira ou não aos fatos da questão." (WHITE, 2006, p. 194) e mesmo assim, não há como um historiador, ou um artista, imitar os fatos, os objetos ou a natureza. Mesmo se forem capazes de narrar, ou pintar, com tamanha objetividade, ainda assim, estariam utilizando a palavra, o texto, a tinta, o pincel. Do mesmo modo, há neste sentido certa ambiguidade, pois quando náo estamos familiarizados com o sistema e náo temos a capacidade de reconhecer as propriedades relevantes, a representação pode ser ambígua. Devemos observar também que representação pode se tornar vaga porque tem a capacidade de exemplificar diversos níveis de generalidade. Nesse sentido, consideremos o conceito de "vaguidade" ${ }^{4}$ de Quine. Para esclarecer a "vaguidade", Quine (2010, p. 167) utiliza, entre outros, um exemplo cromático: o termo verde é vago, pois "À medida que é deixado indeterminado o quão para baixo no espectro, em direção ao amarelo, ou para cima, em direção ao azul, uma coisa pode estar e ainda ser considerada verde [...].”. Para ele, os limites da vaguidade podem ser dissipados à medida que tomamos a comparaçáo de um objeto com outro, como, por exemplo, "o enxofre é mais verde do que sangue, e o céu, do que violetas.” (QUINE, 2010, p. 168). Contudo, Quine observa que não é a ordenação o mais relevante, pois a vaguidade permanece em "mais verde", se comparada a desvios de uma padronagem da cor verde. Entretanto, Quine (2010, p. 168) afirma que "A vaguidade não é incompatível com a precisão.". Nesse sentido, Quine cita o exemplo de Richards, adaptado-o ao domínio da pintura:

\footnotetext{
um pintor com uma paleta limitada pode alcançar representaçôes mais precisas diluindo e combinando suas cores do que um artista de mosaico pode fazê-lo com sua variedade limitada de ladrilhos, e a habilidosa sobreposiçáo de vaguidade tem vantagens semelhantes em relação à união de termos técnicos precisos (QUINE, 2010, p. 169)
}

Dessa forma, segundo Quine, a vaguidade auxilia o enfrentamento da linearidade do discurso. Um expositor acredita que a compreensão de algum conteúdo de uma pintura de carretéis, por exemplo, seja a preparação necessária para compreendermos a série Carretéis. Entretanto, isso não significa que uma pintura de carretéis não possa, ela mesma, ser exposta bem detalhadamente sem, pelo contrário, aludir certas exceções e distinções que demandam compreensão precedente da série Carretéis. Nesse caso, a vaguidade defendida por Quine vem para nos socorrer. Ou seja, uma pintura dos carretéis é vaga e avança para a série Carretéis, e posteriormente recompóe uma pintura dos carretéis. Isso ocorre de tal modo que não se exige que seu fruidor aprenda e desaprenda qualquer falsidade absoluta na enunciação preliminar de uma pintura de carretéis. Do mesmo modo que Quine, Kandinsky aborda a vaguidade da questão cromática. Afirma que

4 Mais esclarecimentos sobre a noção da vaguidade, cf. Quine (2010, p. 167). 
[...] A palavra vermelho não pode ter, na representação que dela fazemos ao ouvi-la, nenhum limite. [...] O vermelho que não vemos, mas que concebemos da maneira mais abstrata desperta, não obstante, uma representação íntima, ao mesmo tempo precisa e imprecisa, de uma sonoridade interior. Esse vermelho que ressoa em nós quando ouvimos a palavra 'vermelho' mantém-se vago e com o que indeciso entre o quente e o frio. $\mathrm{O}$ pensamento o concebe como o produto de imperceptíveis graduaçóes do tom vermelho. É por isso que essa visão totalmente interior pode ser qualificada de imprecisa. Mas, ela é ao mesmo tempo precisa, porque o som interior permanece puro, despojado, sem tendências acidentais nem para o quente, nem para o frio, tendências que culminariam na percepção de detalhes. (KANDINSKY, 1996, p. 74).

A representação da cor na pintura para Kandinsky cumpre a determinação sensível da escolha entre uma gama infinita de vermelhos, o que dá entender que esta seleção possa ser subjetiva. Além disso, deverá considerar a delimitação da superfície que entre as outras cores se modificará entre elas, o que trará por sua presença a subjetividade de suas características e a objetividade em sua ressonância.

Assim, do mesmo modo que a pintura, com suas ressonâncias vinculadas a suas características, todas as verdades possíveis de um fato histórico, de um objeto ou da natureza, só estão contidas no fato histórico, no objeto ou na natureza. Assim, um carretel pintado por Iberê, por mais semelhante que possa ser com o objeto representado, pode ser mais semelhante à outra pintura qualquer, como a de uma árvore, por exemplo, do que ao próprio objeto carretel. Consideremos que um carretel seja objetivamente feito de madeira e que tenha sido representado "realisticamente" em uma pintura por Iberê. Se analisarmos o material nos quais ambos tenham sido elaborados, carretel e pintura, em nada terão de semelhantes. Se ponderarmos a dimensão, mesmo assim serão distintos, pois enquanto um apresenta volumetria o outro é bidimensional. Agora, se compararmos o carretel de maneira com um copo feito com o mesmo material, ambos como objetos, os dois apresentaráo similaridade no que tange a matéria e ao cromatismo, por exemplo. Vejamos que os dois últimos objetos dados como exemplo, não cabem à mesma comparaçáo, pois ambos são semelhantes somente ao que pertence a sua dimensão, cromatismo e materialidade, ou seja, são representaçóes de carretel e de copo. E ainda, se tivermos como parâmetro comparativo sua representaçáo neste contexto, a semelhança pode ser considerada, pois ambas são impressões gráficas sobre papel. Tudo irá depender das propriedades eleitas à comparaçáo.Portanto, se não há satisfaçáo plena, necessária e suficiente, de similaridade entre dois ou mais objetos ao que tange a todas as suas propriedades, exceto quando produzidos em série, não há satisfação plena, necessária e suficiente, à similaridade ao que tange a representaçáo.

\section{A VERDADE NA REPRESENTAÇÃO DOS CARRETÉIS}

O objeto carretel foi para Iberê Camargo não só um tema investigativo, mas foi o agente para sua produção plástica. O repertório de um único elemento foi suficiente, apesar dos contratempos, para conferir ao artista prestígio e o lugar de destaque na história da arte no Brasil. Sobre a originalidade do fazer na obra iberiana Siqueira analisa: "Espátula, pincel, o próprio tubo de tinta transmitem o gesto com uma contundência plástica até 
então desconhecida na arte brasileira.” (2009, p. 61). A série Carretéis desdobrou-se, desde 1958, em mais de vinte anos de pesquisa. Por isso, não se caracteriza, como para a maioria dos artistas, apenas como um período onde o tema é investigado, mas como a própria identidade da trajetória do artista. Durante essa Série muitas foram as fases: figurativa, abstrata, simbólica, sombria ou iluminada, todas culminaram no esgotamento expressivo do objeto. Mesmo depois de a Série ter sido dada com finita, o objeto influenciou e continuou impulsionando os períodos vindouros, como ocorreram com as séries Manequins, Ciclistas e Idiotas.

A liberdade que Iberê exercia em sua obra plástica é coerente a sua posição em relação aos movimentos artísticos tão fertilizados em períodos de sua "formaçáo", e dos quais não se acompadrava. Era homem atento aos acontecimentos e demonstrava preocupação com os nortes da arte de sua época. Porém, a concomitância do movimento abstracionista ${ }^{5}$ e das Bienais de São Paulo no Brasil da década de cinquenta, colocavam em ebulição os paradigmas artísticos, mas não alteravam suas convicçóes em relação a sua produção. Criticava essa modernizaçáo da arte com certa rabugice e seguia seu trabalho no silêncio de suas crenças, porém defendia a liberdade frente as noções de representação.

Sobre este olhar, tanto para Wittgenstein quanto para Iberê o que é válido para a representação é o mesmo para expressão. É como substituir a descrição verbal pela representação e o objeto factual por sua interpretação. Podemos então, tomar esta concepção como exemplo da pintura do carretel de uma fase da pesquisa de Iberê posterior à fase inicial (Figura 1), onde as obras foram intituladas Estruturas (Figura 2).

\section{Figura 1 - Iberê Camargo Carretéis, 1958 - Óleo sobre tela, $65 \times 92 \mathrm{~cm}$ [Coleção Alice Soares de Souza - Rio de Janeiro-RJ]}

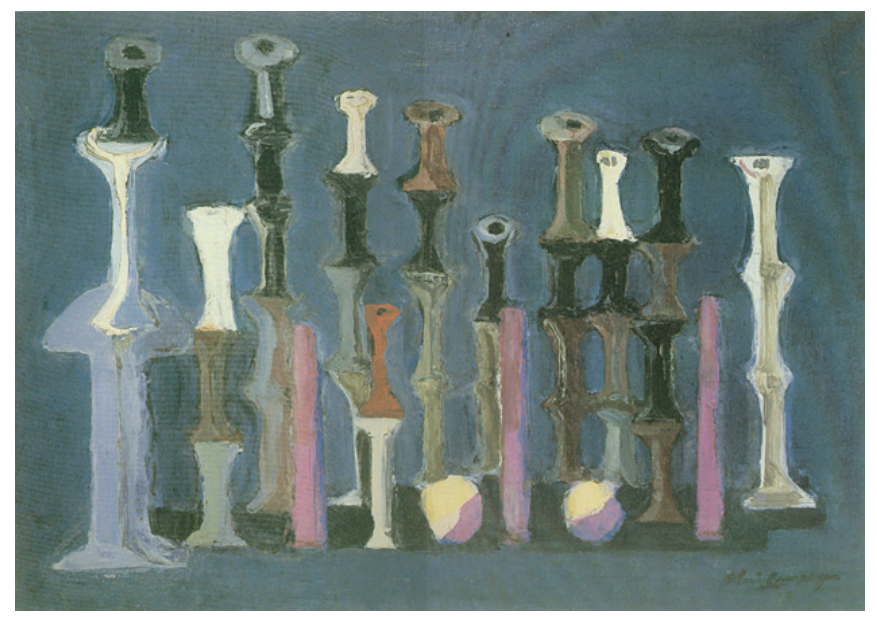

Fonte BERG (1985) s/n. p.

5 Movimento artístico atribuído inicialmente à produção do russo Wassily Kandinsky (1866-1944), por volta de 1910 e que abandona a concepção de arte como imitação da natureza, buscando interpretá-la por meio de formas alheias ao seu reconhecimento imediato. (CHILVRES, 1996) 
Figura 2 - Iberê Camargo Estrutura, 1961 - Óleo sobre tela - 88 x 133 cm

[Coleção Museu Nacional de Belas Artes - Rio de Janeiro]

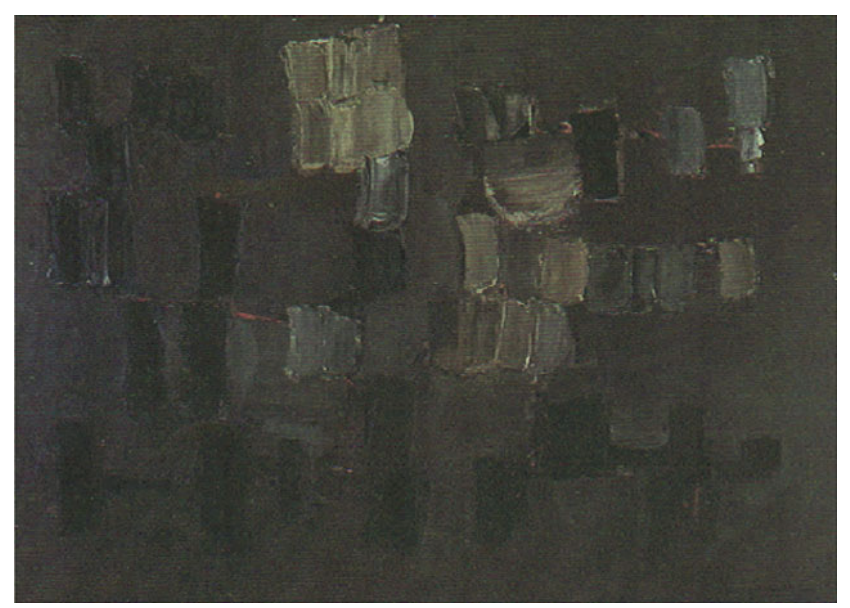

Fonte: BERG (1985, s/n p.)

$\mathrm{Na}$ fase anterior, o tema "carretel" está representado sobre uma base a qual entendemos como uma mesa. Temos conhecimento direto daquilo que os objetos representam por meio de suas propriedades estruturais que estão associadas ao próprio objeto. Como um conjunto de símbolos estéticos pictóricos, as pinturas representacionais figurativas pertencem ao que entendemos como um "sistema" representacional, então podemos dizer que esta é uma pintura representacional figurativa. Já na fase posterior, a da Estruturas o artista afirma que "Pelas estruturas de carreteis, cheguei ao que se chama, no dicionário da pintura, arte abstrata. Nesse período, o ritmo é gestual, porém dirigido, não mera impressáo de um gesto qualquer." (CAMARGO, 2009, p. 134). E é justamente a partir deste período, o período de "desconstrução" da forma que o objeto é também desvinculado de sua objetividade, pois são representados como objetos que perderam sua função inicial de rodopiar conduzindo a linha para a costura materna. $\mathrm{Na}$ lembrança do objeto a sua função é transformara-se em brinquedos, em personagens de batalhas entre pica-paus e maragatos.

Na obra Carretéis (1958), a representação da verdade do carretel está no exercício minucioso sobre o objeto que vai alargando as possibilidades de simbolizaçáo e evidenciando na obra um caráter cada vez mais pessoal. Desse modo, o carretel passa a fazer parte do repertório do artista e será cultivado como a figura responsável em transportar todas as propriedades referentes à pintura, como formas, cores e texturas, assim como dará forma, cor e textura à suas lembranças de infância. O que a pintura Carretéis exprime depende das convençóes culturais, mas as propriedades expressas na obra foram adquiridas e exploradas pelo artista sem nenhuma inquietação com normas de perfeição estabelecidos. Para ele "Não há um ideal de beleza, mas o ideal de uma verdade pungente e sofrida que é minha vida, a tua vida, é nossa vida, nesse caminhar no mundo." (CAMARGO, 2009, p. 31).

Para a teoria de símbolos de Goodman (1976), entre o modo de referência expressão na pintura, o destaque dado dependerá do artista, assim como da obra. Nesse caso, podemos 
dizer que a ênfase na pintura Carretéis está mais próxima da representação objetiva, pois está mais associada às convençóes do sistema simbólico com os quais estamos familiarizados. O que nos autoriza a classifica-la como uma obra figurativa que está mais próxima do realismo, pois ao observarmos a obra relacionamo-la imediatamente com o objeto que conhecemos. Segundo D’Orey (1999, p. 788), "quando a arte é considerada no âmbito de uma teoria de símbolos, o realismo deve ser considerado uma forma de correção." Entretanto, como vimos, o realismo não garante a qualidade da obra. É necessário investigarmos outras propriedades que a princípio podem ser mais difíceis, como, por exemplo, a apreciação das características formais que a pintura explicita. O novo sentido de realismo tomado por Goodman (1978, p. 131), no qual podemos dizer que uma obra é correta, é o realismo como "revelação", ou seja, o artista revela-nos aspectos invisíveis, outras possibilidades artísticas atingindo um novo grau de realismo. As características adotadas por Iberê ao representar os carretéis na pintura acima, originam-se de maneiras de representar formas já esgotadas ao longo da história da pintura. Nestas formas, sejam abstratas ou realistas há uma combinação que segundo Kandinsky apresentam uma infinidade de possibilidades onde

[...] O artista é e permanece livre para combinar os elementos abstratos e os elementos objetivos, para realizar uma escolha entre a série infinita das formas abstratas ou do material que os objetos lhe fornecem - em outras palavras, é livre para escolher seus próprios meios. [...] Uma forma hoje desprezada e desacreditada, que parece situar-se à margem da grande corrente da pintura, aguarda simplesmente seu mestre. (KANDINSKY, 1996, p. 159).

Como vimos, Iberê esteve livre para combinar elementos abstratos e elementos objetivos, mas estudou e sofreu influências de momentos históricos da arte para criar novas possibilidades formais, ou despertá-la. Assim o sistema simbólico de representação anterior foi substituído por outro. Isso nos permite afirmar que a relatividade presente na expressão deriva da interpretação que cada obra pode gerar no fruidor, o que está vinculado não somente ao espaço simbólico exposto, mas ao equipamento intelectual que dispóe o fruidor. Portanto, ao interpretarmos a pintura Carretéis dizemos que a propriedade “pesada” expressa está relacionada ao universo pictórico adotado por Iberê, o que também poderá estar presente no conjunto de suas obras dentro do que compreende a primeira fase da série Carretéis, a qual estamos familiarizados.

No caso da primeira obra a explicação mais comum referente à representação, a que considera a semelhança, poderia ser eficaz, pois há alguma afinidade no que diz respeito ao aspecto formal dos objetos representados. Neste sentido, segundo Platão (passagem 595 a - c, 2009), a representação é aparente. Entretanto, como a representação não é simétrica e nem reflexiva, como a semelhança, não satisfaz a questão. Não é simétrica porque o carretel pode náo estar relacionado diretamente, em tamanho ou cor, por exemplo, com o objeto concreto. Não é reflexiva porque o objeto carretel foi representado no quadro, mas o carretel objeto não representa o quadro. Assim sendo, o carretel representado é mais semelhante à outra pintura do que ao objeto carretel. Do mesmo modo, é mais semelhante a uma lembrança do artista, que como algo intocável e individual, edifica os carretéis como imagens também simbólicas e subjetivas. 
Já na obra Estrutura (1961), a representação se afasta ainda mais da realidade do objeto e ostenta algumas probabilidades que uma figura geométrica, o quadrilátero, pode revelar formalmente distribuindo-se em todo espaço compositivo. O desenho que representa o carretel é sintetizado por meio da forma quadrangular, mas náo pode explicitar em apenas uma descrição o mistério metafórico. As cores empregadas são compostas em sua maioria com a mistura do preto e do branco e com uma pequena porção de verde. Estas tonalidades são acentuadas em partes da obra quando a cor verde está mais presente. Entretanto, os matizes sáo estruturados dentro de um limite cromático e também de graus de generalidade. Podemos dizer que o verde acinzentado usado pelo artista nos quadriláteros situados na parte inferior esquerda da obra é mais cinza e menos verde do que aquele usado nos quadriláteros superiores. Estes são mais claros do que os quadriláteros mais escuros da extrema esquerda e da parte inferior da pintura. Não podemos afirmar, no entanto, o quanto o verde está próximo do amarelo ou do azul no espectro cromático e qual verde vemos na verdade. Os carretéis sáo representados no espaço, a linha de base desaparece e transforma-se demonstrando que na linguagem da pintura náo há distinção entre espaço e corpo. Aqui a verdade do objeto está no desenho do carretel que é sintetizado chegando à simplicidade da geometria quadrangular. Agora, a cor torna-se mais dramática e domina o plano pela densidade do valor escuro. Figura e fundo confundem-se pelas pinceladas fartas de tinta e tomam direçóes antagônicas. O equilíbrio dos carretéis, antes cuidadosamente enfileirados, desestrutura-se e dá movimento a composição. Consequentemente, "As últimas referências explícitas ao mundo exterior se apagam, e agora os carretéis que já não aparecem carretéis, flutuam no espaço do peso da condição natural.” (GULLAR in ARTISTAS BRASILEIROS no 1, 1983, s/n. p.). Os carretéis desta fase aparecem sintetizados formalmente. Indiretamente tratam o "objeto como um exemplar de propriedades que se aplicam a outras coisas” (D'OREY, 1999, p. 783), mas ainda estabelecem alguma associação com o objeto. Nesta obra o desenho do carretel é sintetizado alcançando a simplicidade da figura geométrica quadrangular. A figura geométrica aliada à cor "possui seu próprio som interior" (KANDINSKY, 1996, p. 75), e reciprocamente o valor cromático é acentuado por sua forma quadrangular, o que nos leva a crer que a subjetividade da escolha cromática está envolvida na objetividade da forma. Ou seja, Iberê escolheu representar o carretel como um quadrilátero e este determinou com sua forma, os limites cromáticos.

O reconhecimento formal do carretel, ainda que desconstruído, nos permite fazer relaçóes entre o objeto que avaliamos diferente, ao mesmo tempo em que nos permite fazermos distinçóes entre o objeto que consideramos igual. Estas distinções são possíveis em razão davariação da expressão na pintura, onde esta depende do artista assim como da própria obra, seja plástica ou textual. No caso da pintura iberiana, o aspecto mais relevante está relacionado à expressão, pois o referencial carretel foi interpretado dentro de um sistema tomado por Iberê, para dar lugar a qualidades sensoriais (dinamismo) e emocionais extraordinários. O quadro é um ambiente dinâmico que degenera a forma, mas que mantém a verdade através damemória do carretel evocada pelas lembranças de uma infância distante, mas estancada pela imagem que, fora do corpo, é percebida pela afecção do corpo (BERGSON, 1999). 
Sob o ponto de vista holístico de Rorty (1994) a reconstrução elaborada para a representação do objeto carretel da memória de infância de Iberê passa pela conservação entre o dado, o contingente e o necessário. Isto é, o carretel é um dado que factualmente existiu na infância do artista, presente como objeto de costura materna que após seu descarte transformava-se em brinquedo para menino. O carretel é contingente, no sentido de transitório, pois foi mutante pelas várias fases apanhadas dentro da mesma Série, e assim a ele foiacrescido o que a mente do artista desejou. E é necessário porque o carretel náo foi somente um tema, mas se tornoumotivo para o artista atuar como produtor de arte, e desse modo, ultrapassou a simples racionalidade para reconstruí-la por meio do conhecimento. Outro aspecto abordado por Rorty (1994) é aquilo "que é bom para acreditarmos" e neste sentido Iberê julga bom acreditar como a representação "verdadeira" aquela onde cada artista busca seu modo de representar independente da técnica empregada, pois para ele a técnica "é o resultado de cunho pessoal que o artista obtém no emprego de processos tradicionais. Sei que não é fácil fazer seu o que é de todos, mas é exatamente isso que faz existir Rembrandt, Goya, Piranesi e todos os outros que conhecemos." (CAMARGO, 2006, p. 52). E é ao estudar os grandes mestres da pintura na Europa que o artista acredita que a "mentira" contada pelos grandes mestres é tão bem "contada" que passa a ser "verdade". E para Iberê a verdade na pintura está contida no que sente e não no que vê, "A verdadeira pintura não é uma narrativa de fatos, mas o próprio fato" (CAMARGO, 2012, p. 26).

Costuramos assim uma cumplicidade entre Iberê e Wittgenstein através do seguinte fragmento:

\footnotetext{
$\mathrm{Na}$ verdade, quando nós interpretamos uma figura, nós vemos ou supomos ver alguma coisa que está naquela figura, que está dentro dela; aquilo é um ser, é uma coisa viva e eu tenho essa coisa de penetrar, quer dizer, de sugar, como se eu quisesse te roubar a alma, eu tenho que tirar de ti tudo o que tens de vital (CAMARGO, 2006, p. 63).
}

Outro aspecto referente à representação e a verdade tem a ver com a simbolização. Como vimos para Chartier (1989) a representação tem a capacidade de prover a realidade que representa, construindo um mundo análogo de símbolos de determinada cultura. Desse modo, podemos ao acomodara produção do artista Iberê na série Carretéis como uma operação corporal aliada a uma operação mental, visto que o corpo não opera sozinho, e deste modo, cria sentido a uma realidade. A representação das memórias de infância é então construída sobre o mundo do artista e "não só se coloca no lugar deste mundo", como faz com que o artista apreenda a realidade e regule a sua existência, ou seja, a sua verdade.

\section{CONSIDERAÇÕES FINAIS}

Este texto buscou esclarecer algumas noçóes de representação com a intenção de verificar a direção vantajosa do debate no que diz respeito à narrativa histórica e a produção artística, pois assim como a história, a estética prossegue com fendas que permitem constantes estudos. Examinamos que a pretensão de fundar a representação como 
semelhança é ineficaz, sobretudo porque uma pintura não pode representar um objeto sendo ao mesmo tempo uma imagem de outro objeto. Vimos também, que a explicação causal não fornece um esclarecimento adequado da representação. Outra noçâo exposta neste estudo foi a de intencionalidade e que também não responde satisfatoriamente o que se busca, dada à impossibilidade de um conhecimento anterior ao que pode pretender um historiador ou um artista. Vimos ainda, que há consonância entre os autores aqui abordados, quanto à existência de várias versóes de mundos pautados aos modos de representação. Desse modo, o caráter revolucionário das teorias quanto à constituição categorial da representação, ainda deixa perguntas. E neste sentido, assim como a construção e a leitura da narrativa histórica e da obra de arte, abre possibilidades às práticas diferenciadas e às intermináveis discussóes e interpretaçóes.

A intenção deste texto, além de expor algumas noções de representação, não foi responder $o$ que são as obras de série Carretéis de Iberê Camargo, mas demonstrar como são estas obras e, nesse sentido, avançar alguns passos em direção à análise estética referente a uma compreensão e a um alargamento da noção de representação e da percepçáo da verdade diante das Artes Visuais. 


\section{REFERÊNCIAS:}

BERGSON, Henri. Matéria e memória: ensaio sobre a relação do corpo com o espírito; tradução Paulo Neves. - 2- ed. - São Paulo: Martins Fontes, 1999.

BURKE, Peter. O que é historia cultural?; tradução: Sérgio Goes de Paula. Rio de Janeiro: Jorge Zahar Ed., 2005.

CAMARGO, Iberê. Gaveta dos guardados. São Paulo: Cosac \& Naify, 2009.

. In ZIELINSKY, Mônica. Iberê Camargo: catálogo raisonné: vol. I/Gravuras. São Paulo: Cosac \& Naify, 2006.

No tempo. Porto Alegre: Fundação Iberê Camargo, 2012.

CASSIRER, Ernst. A filosofia das formas simbólicas; tradução Marion Fleischer. São Paulo: Martins Fontes, 2001.

CHARTIER, Roger. Defesa e ilustração da noção de representação. Fronteiras, DouradosMS, v. 13, n. 24, pp. 15-29, jul./dez. 2011.Disponível em: <http:/www.ufrgs.br/gthistoriaculturalrs/nocaoderepresentacao.pdf> Acesso em: 30 mai. 2016.

. 1989. O mundo como representação. Estudos Avançados, São Paulo, v. 5, n. 11, pp. 173-191. Disponível em: <http://www.revistas.usp.br/eav/article/view/8601/10152> Acesso em: 21 jul. 2016.

\& BOUDIER, Pierre. O sociólogo e o historiador. Tradução Guilherme João de Freitas Teixeira - Belo Horizonte: Autêntica Editora, 2012.

D'OREY, Carmo. A exemplificação na arte: um estudo sobre Nelson Goodman. Lisboa: Fundação Calouste Gulbenkian, 1999.

EMEARTH, Elizabeth. Beyond History. In: A história refigurada. São Paulo: Contexto, 2014.

GOMBRICH, E. H. Arte e ilusão: um estudo da psicologia da representação pictórica; tradução Raul de Sá Barbosa. São Paulo: WMF Martins Fontes, 2007.

GOODMAN, Nelson. Languages of art: an approach to a theory of syimbols. Indianápolis and New York, Bobb-Merril, 1976.

Of mind and other matters. Cambridge: Harvard UP. 1984. (Versão espanhola de T. Breton: De La mente y otras materias. Madrid: Visor, 1995.

JENKINS, Keith. Ordem (ns) do dia. In: A história refigurada. São Paulo: Contexto, 2014.

. O que é a história. In: A história repensada. São Paulo: Contexto, 2001.

KANDINSKY, Wassily. Do espiritual na arte; tradução Álvaro Cabral - 2. ed. - São Paulo: Martins Fontes, 1996.

PLATÃO. A república. São Paulo: Martin Claret, 2009. 
QUINE, Willard Van Orman. Palavra e objeto; tradução Sofia Inês Alborz Stein e Desidério Murcho. Petrópolis, RJ: Vozes, 2010.

RICOEUR, Paul. A memória, a história, o esquecimento; tradução Alain François [et al]. Campinas: Editora da Unicamp, 2007

. A metáfora viva. São Paulo: Loyola, 2000-2005.

RORTY, Richard. A filosofia e o espelho da natureza; tradução Antônio Trânsito - Rio de Janeiro: Relume-Dumará, 1994.

Objetivismo, relativismo e verdade; tradução Marco Antônio Casanova. Rio de Janeiro: Relume-Dumará, 1997.

WHITE, Hayden. Enredo e verdade na escrita da história In: MALERBA, Jurandir (org). A história escrita. São Paulo: Contexto, 2006.

Ficción histórica, história Ficcional e realidade. In. Ficción histórica, historia e realidade histórica. Buenos Aires: Prometeo, 2010.

Meta-história: a imaginação histórica do século XIX; Tradução José Laurênio de Melo. São Paulo: Editora de Universidade de São Paulo, 1995.

.Trópicos do discurso: ensaios sobre a crítica da cultura. Tradução Alípio Correia de Franca Neto. Editora da Universidade de São Paulo, 1994.

WITTGENSTEIN, Ludwig. Investigaçóes filosóficas; tradução José Carlos Bruni - 3. ed. - São Paulo: Abril Cultural, 1984.

WOLlHEIM, Richard. A arte e seus objetos; tradução Marcelo Brandão Cipolla. São Paulo: Martins Fontes, 1993.

A pintura como arte; tradução Vera Pereira. São Paulo: Cosac \& Naify, 2002.

Artigo recebido em 09/08/2017

Artigo aceito em 07/12/2017 